\title{
Gentamicin resistance in clinical isolates of Escherichia coli encoded by genes of veterinary origin
}

\author{
A. P. JOHNSON, LOUISE BURNS, N. WOODFORD, E. J. THRELFALL*, JAY NAIDOO†, \\ E. M. COOKE $†$ and R. C. GEORGE
}

Antibiotic Reference Unit, Laboratory of Hospital Infection and * Laboratory of Enteric Pathogens, Central Public Health Laboratory, Colindale Avenue, London NW9 $5 H T$

\begin{abstract}
Summary. Seven $(27 \%)$ of 26 gentamicin-resistant human clinical isolates of Escherichia coli were resistant to the veterinary aminoglycoside antibiotic apramycin. A gentamicin-resistant Klebsiella pneumoniae isolate from a patient infected with gentamicin/apramycin-resistant $E$. coli was also resistant to apramycin. DNA hybridisation studies showed that all gentamicin/ apramycin-resistant isolates contained a gene encoding the enzyme 3-N-aminoglycoside acetyltransferase type IV (AAC[3]IV) that mediates resistance to gentamicin and apramycin in bacteria isolated from animals. Seven of the eight gentamicin/apramycin-resistant isolates were also resistant to the veterinary antihelminthic agent hygromycin $\mathrm{B}$, a phenomenon observed previously in gentamicin/apramycin-resistant Enterobacteriaceae isolated from animals. Resistance to gentamicin/apramycin and hygromycin B was cotransferable in six of the isolates. Restriction enzyme analysis of plasmids in apramycinresistant transconjugants derived from $E$. coli and $K$. pneumoniae isolates from the same patient were virtually identical, suggesting that inter-generic transfer of plasmids encoding apramycin resistance had occurred in vivo. These findings support the view that resistance to gentamicin and apramycin in clinical isolates of $E$. coli results from the spread of resistant organisms from animals to man, with subsequent inter-strain or inter-species spread, or both, of resistance genes on transferable plasmids.
\end{abstract}

\section{Introduction}

Apramycin is an aminoglycoside antibiotic which has been used extensively in veterinary medicine since 1980. ${ }^{1}$ However, it has not been used therapeutically in man. Although early studies indicated that resistance to apramycin was rare in bacteria from either human or veterinary sources, ${ }^{2,3}$ resistant organisms, particularly Escherichia coli and Salmonella spp., have been isolated from the faeces of farm animals treated with apramycin. ${ }^{4}$ Investigation of the mechanism of resistance in isolates from farm animals in the USA showed that the organisms produced a novel aminoglycoside-modifying enzyme subsequently designated (3) N-aminoglycoside acetyltransferase type IV (AAC[3]IV). ${ }^{5}$ This enzyme acetylated not only apramycin but other aminoglycosides including gentamicin and tobramycin, which are used to treat serious infections in man. ${ }^{5}$ Subsequent studies have shown a similar mechanism of resistance in apramycin-resistant Salmonella spp. and E. coli isolated from farm animals in the $\mathrm{UK}^{1,6,7}$ and France. ${ }^{8}$

Received 8 June 1993; accepted 17 Sept. 1993.

$\dagger$ Present address: Unilever Research, Port Sunlight Laboratory, Wirral L63 3JW.

‡ Present address: Public Health Laboratory Service HQ, Colindale Avenue, London NW9 5DF.
The observation that apramycin usage in veterinary medicine may result in carriage and faecal excretion by farm animals of enteric bacteria cross-resistant to gentamicin, gave rise to concern that these resistant bacteria might spread to man. Indeed, in 1986, Threlfall and co-workers reported the isolation of $S$. typhimurium phage type $204 \mathrm{c}$ resistant to apramycin and gentamicin from both cattle and man. ${ }^{6}$ Subsequently, other species of Enterobacteriaceae resistant to apramycin and gentamicin due to production of AAC(3)IV have been isolated from patients in hospitals in Belgium, ${ }^{9}$ Spain $^{10}$ and the UK. ${ }^{11}$ In view of this, a collection of gentamicin-resistant Enterobacteriaceae obtained from patients in the UK were assessed for resistance to apramycin, and resistant organisms detected were studied with regard to the mechanism and genetics of their resistance.

\section{Materials and methods}

\section{Apramycin-resistant isolates}

Twenty-six non-faecal clinical isolates of gentamicin-resistant $E$. coli referred to the Laboratory of Hospital Infection during 1987-1988 were screened for resistance to apramycin by an agar incorporation 
Table I. Clinical isolates of gentamicin/apramycin-resistant Enterobacteriaceae

\begin{tabular}{|c|c|c|c|c|c|c|}
\hline Species & Isolate no. & Patient & Location & Source & O Serogroup & Resistance profile \\
\hline E. coli & E179 & A & Grimsby & Biliary drainage tube & 83 & Gm, Apr, Tob, Hyg \\
\hline K. pneumoniae & K 180 & A & Grimsby & Biliary drainage tube & - & Gm, Apr, Tob, Hyg, Amp \\
\hline E. coli & E444 & B & Grimsby & Urine & 23 & Gm, Apr, Tob, Hyg, Amp, Tet, Trm \\
\hline E. coli & E545 & $\mathrm{C}$ & Grimsby & Urine & 117 & Gm, Apr, Tob, Hyg, Amp, Tet, Trm \\
\hline E. coli & E548 & D & Taunton & Urine & NT & Gm, Apr, Tob, Hyg, Tet \\
\hline E. coli & E550 & $\mathrm{E}$ & Taunton & Urine & 8 & Gm, Apr, Tob, Hyg, Tet \\
\hline E. coli & E597 & $\mathrm{F}$ & Edinburgh & Not known & 75 & Gm, Apr, Tob, Hyg, Amp \\
\hline E. coli & E635 & G & Southampton & Urine & 8 & Gm, Apr, Tob, Hyg, Amp, Trm \\
\hline
\end{tabular}

Gm, gentamicin; Apr, apramycin; Tob, tobramycin; Hyg, hygromycin B; Amp, ampicillin; Tet, tetracycline; Trm, trimethoprim; NT, nontypable.

breakpoint method with apramycin at a concentration of $16 \mathrm{mg} / \mathrm{L}$. Seven isolates were found to be resistant. A gentamicin-resistant isolate of Klebsiella pneumoniae obtained simultaneously with gentamicin/apramycinresistant $E$. coli from one patient was also found to be resistant to apramycin. The sources of the eight apramycin-resistant isolates together with their serotypes and antibiograms are given in table $\mathbf{I}$.

\section{Determination of minimum inhibitory concentrations (MICs)}

MICs of several antimicrobial agents, including apramycin and hygromycin B (kindly provided by Lilly Research Laboratories), were determined by an agar dilution method in Isosensitest agar supplemented with lysed horse blood $2 \% \mathrm{v} / \mathrm{v}$. Serial two-fold dilutions of each antimicrobial agent were incorporated into the medium and plates were inoculated by a multipoint inoculator (Diamed Diagnostics) with an inoculum of $10^{4}-10^{5} \mathrm{cfu} /$ spot.

\section{Plasmid analysis}

Plasmids were extracted by the method of Kado and $\mathrm{Liu}^{12}$ and separated by electrophoresis in agarose $0.7-0.8 \% \mathrm{w} / \mathrm{v}$ gels. The molecular sizes of plasmids were estimated by comparison with plasmids of known size. In some experiments, extracted plasmids were digested with restriction endonucleases under conditions specified by the enzyme manufacturer (Boehringer Mannheim), and the resulting fragments were separated by agarose gel electrophoresis. The sizes of restriction fragments were determined by comparison with fragments of linear DNA of known size (DNA mol.-wt markers I and II; Boehringer Mannheim).

\section{Transfer of apramycin resistance}

Conjugation experiments were performed overnight in stationary broth culture at $37^{\circ} \mathrm{C}$. The recipient organism was $E$. coli strain 14R525 which is plasmidfree and resistant to nalidixic acid. Transconjugants were detected by plating the mixture of donor and recipient organisms on nutrient agar containing nalidixic acid $50 \mathrm{mg} / \mathrm{L}$ and apramycin $16 \mathrm{mg} / \mathrm{L}$.

\section{Probe for gene encoding $A A C(3) I V$}

The DNA probe specific for the gene encoding production of AAC(3)IV consisted of a 740-bp SacI fragment of plasmid pWP701. ${ }^{13}$ Plasmid pWP701 was purified on a Qiagen column (Qiagen pack 500, Diagen) and digested overnight with $\mathrm{Sac}$ I. The 740-bp fragment was separated by electrophoresis through an agarose $1 \% \mathrm{w} / \mathrm{v}$ gel, extracted from the gel by Prep-aGene (BioRad), and labelled with digoxigenin from a commercially available kit (Non-radioactive DNA Labelling and Detection Kit, Boehringer Mannheim).

\section{Preparation of DNA for hybridisation studies}

For dot-blot assays, DNA extracted from bacteria as described previously ${ }^{14}$ was denatured by heating at $95^{\circ} \mathrm{C}$ for $10 \mathrm{~min}$, cooled on ice and spotted on to nylon membranes (Hybond, Amersham), and allowed to dry in air. The membranes were baked at $80^{\circ} \mathrm{C}$ for $2 \mathrm{~h}$ then stored at room temperature until required.

For Southern blot analysis of plasmid DNA, plasmids were extracted and subjected to gel electrophoresis as described above, then transferred to nylon membranes with vacuum blotting equipment (Vacugene, Pharmacia LKB). The membranes were baked at $80^{\circ} \mathrm{C}$ for $2 \mathrm{~h}$ to fix the DNA and then stored at room temperature.

\section{Results}

\section{Antimicrobial resistance}

The MICs of apramycin, gentamicin, tobramycin and hygromycin B for the eight clinical isolates are shown in table II. All eight isolates were resistant to apramycin (MIC $\geqslant 1024 \mathrm{mg} / \mathrm{L})$, gentamicin $(\mathrm{MIC} 16-32 \mathrm{mg} / \mathrm{L})$ and tobramycin (MIC > $32 \mathrm{mg} / \mathrm{L}$ ) but were sensitive to amikacin (MIC $\leqslant$ $2 \mathrm{mg} / \mathrm{L}$ ). All of the clinical isolates had MICs of hygromycin $\mathrm{B}$ of $\geqslant 512 \mathrm{mg} / \mathrm{L}$ with the exception of isolate E635 which had an MIC of hygromycin B of $64 \mathrm{mg} / \mathrm{L}$. One isolate (E550) lost resistance to aminoglycosides during subculture in the laboratory. This sensitive variant was designated E550S. The apramycin-sensitive variant E550S, E. coli strain 14R525 
Table II. Antimicrobial resistance and DNA hybridisation reactions of apramycin-resistant clinical isolates and transconjugants .

\begin{tabular}{|c|c|c|c|c|c|c|}
\hline \multirow{2}{*}{ Organism } & \multicolumn{4}{|c|}{$\mathrm{MIC}(\mathrm{mg} / \mathrm{L})$ of } & \multicolumn{2}{|c|}{ Hybridisation of probe* } \\
\hline & apramycin & gentamicin & tobramycin & hygromycin B & Whole-cell DNA $\dagger$ & Plasmid DNA \\
\hline E179 & 1024 & 32 & $>32$ & 512 & + & + \\
\hline $\mathrm{E} 179 \mathrm{Tc}$ & 1024 & 32 & $>32$ & 512 & + & + \\
\hline K180 & 1024 & 32 & $>32$ & 1024 & + & + \\
\hline $\mathrm{K} 180 \mathrm{Tc}$ & 1024 & 32 & $>32$ & 512 & + & + \\
\hline $\mathrm{E} 444$ & 1024 & 16 & $>32$ & 512 & + & - \\
\hline E444 Tc & 1024 & 16 & $>32$ & 512 & + & + \\
\hline E548 & 2048 & 32 & $>32$ & 512 & + & + \\
\hline E548 Tc & 2048 & 32 & $>32$ & 512 & + & + \\
\hline E550 & 2048 & 32 & $>32$ & 512 & + & + \\
\hline $\mathrm{E} 550 \mathrm{Tc}$ & 2048 & 32 & $>32$ & 512 & + & + \\
\hline E550S & 16 & $\leqslant 1$ & $\leqslant 1$ & 64 & - & - \\
\hline E597 & 2048 & 32 & $>32$ & 512 & + & - \\
\hline E597 Tc & 2048 & 32 & $>32$ & 512 & + & + \\
\hline E545 & 2048 & 32 & $>32$ & 512 & + & + \\
\hline E635 & 2048 & 32 & $>32$ & 64 & + & + \\
\hline $14 \mathrm{R} 525$ & $\leqslant 8$ & $\leqslant 1$ & $\leqslant 1$ & 32 & - & - \\
\hline
\end{tabular}

Tc, transconjugant.

* 740-bp SacI fragment of plasmid pWP701. ${ }^{13}$

$\dagger$ Dot blots.

$\ddagger$ Southern blots of plasmid DNA.

and four other apramycin-sensitive clinical isolates of E. coli had MICs of hygromycin B in the range $32-64 \mathrm{mg} / \mathrm{L}$.

There was inter-isolate variation with regard to susceptibility to tetracycline, ampicillin and trimethoprim (table I) but all the isolates were susceptible to ciprofloxacin, chloramphenicol, cefuroxime, cefotaxime and ceftazidime.

\section{Plasmid content of clinical isolates}

With the exception of isolates E179 and K180, all the gentamicin/apramycin-resistant isolates exhibited distinct plasmid profiles; the plasmids from isolates from the same geographical area varied with regard to both number and molecular sizes. Isolates E179 and $\mathrm{K} 180$, which were isolated from the same clinical source, each contained a single plasmid of $c .90 \mathrm{~kb}$. All the other isolates contained either three or four plasmids which ranged in size from $1.5 \mathrm{~kb}$ to $c .90 \mathrm{~kb}$.

\section{Transfer of apramycin resistance}

Apramycin-resistant transconjugants were obtained from six of the eight clinical isolates (E179, K180, E444, E548, E550 and E597) (table II). All the apramycin-resistant transconjugants were resistant to gentamicin, tobramycin and hygromycin B (table II). Plasmid analysis showed that transconjugants obtained from three isolates (E179, K180 and E597) contained a single high mol. wt plasmid of $c .90 \mathrm{~kb}$. Transconjugants from isolate E548 contained two plasmids of c. $90 \mathrm{~kb}$ and $4.5 \mathrm{~kb}$, whereas transconjugants from isolate E550 contained two plasmids of c. $90 \mathrm{~kb}$ and $6.8 \mathrm{~kb}$. In contrast, a series of transconjugants from isolate E444 contained two or three plasmids, $50-70 \mathrm{~kb}$ in size, many of which did not align with plasmids present in the donor, presumably reflecting molecular re-organisation of the plasmids during conjugation. For further study of this isolate, one transconjugant was chosen which contained two plasmids of $c .50 \mathrm{~kb}$ and $60 \mathrm{~kb}$ respectively, the larger of which aligned with a plasmid present in the donor.

Restriction enzyme digestion analysis showed that the single plasmids present in the transconjugants derived from isolates E179 and K180 were virtually identical. EcoRI digests of both plasmids each comprised a series of 14 similar fragments, from 1.2 to $23 \mathrm{~kb}$ in size (figure). The plasmid in the transconjugant derived from isolate E179 differed from the plasmid in the transconjugant from isolate K180 in that the latter plasmid contained a unique EcoRI fragment of $c .4 \mathrm{~kb}$ (figure). A similar type of result was obtained with ClaI. In contrast, the EcoRI and ClaI digestion profiles of the single plasmid in the transconjugant from isolate E597 appeared quite distinct (data not shown).

\section{Hybridisation studies}

In dot-blot assays, the DNA probe specific for the gene encoding AAC(3)IV hybridised with DNA extracted from each of the apramycin-resistant clinical isolates. DNA extracted from five isolates of $E$. coli sensitive to apramycin and the apramycin-sensitive variant of isolate E550 (E550S) failed to hybridise with the probe.

When Southern blots of plasmid preparations of the apramycin-resistant clinical isolates were tested, a single plasmid in each of six isolates (E179, K180, E545, E548, E550 and E635) hybridised with the 


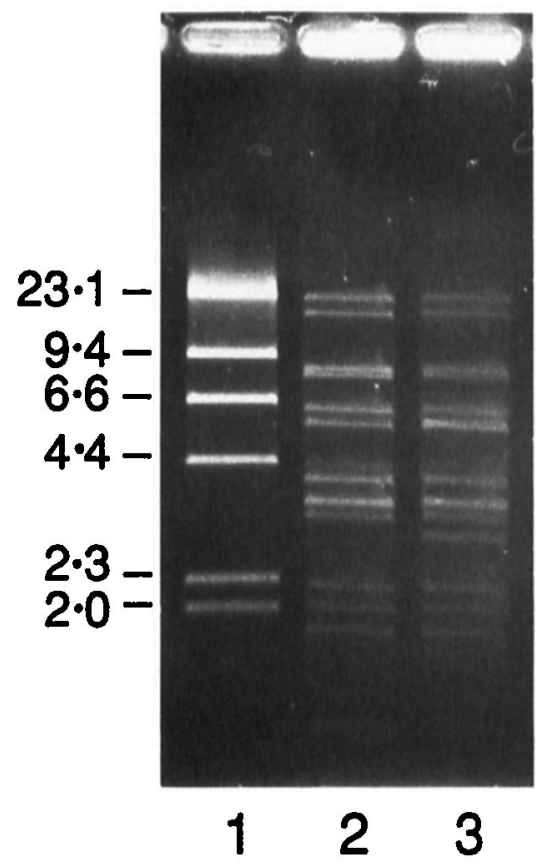

Figure. EcoRI digests of plasmids of apramycin-resistant transconjugants from isolates E179 and K180. Lane 1, molecular size (kb) markers; 2, transconjugant derived from E179; 3, transconjugant derived from $\mathrm{K} 180$.

probe. The size of the plasmids that hybridised with the probe ranged from $c .70$ to $90 \mathrm{~kb}$. With two isolates (E444 and E597), hybridisation of the probe with plasmid DNA was not observed. In subsequent experiments, Southern blots of plasmids from isolates exhibiting transferable resistance together with plasmids from their respective transconjugants were examined. A single plasmid of $c .90 \mathrm{~kb}$ that hybridised with the probe was observed in isolates E179, K180, E548, E550 and their respective transconjugants. As before, no hybridisation was observed with plasmids from isolates E444 and E597, but a plasmid of c. $70 \mathrm{~kb}$ in the transconjugant from isolate E444, and a plasmid of c. $90 \mathrm{~kb}$ in the transconjugant from isolate E597 did hybridise with the probe.

\section{Discussion}

Studies of gentamicin/apramycin-resistant Enterobacteriaceae isolated from animals have shown that resistance is due to production of the enzyme AAC(3)IV. ${ }^{5-8}$ Molecular analysis of an apramycinresistant Salmonella sp. of animal origin ${ }^{13}$ further showed that the gene encoding AAC(3)IV is closely linked to a gene encoding resistance to the aminocyclitol antibiotic hygromycin B, which has been used as an antihelminthic agent in farm animals. Therefore, it was interesting to note that each of the eight clinical isolates of gentamicin/apramycin-resistant Enterobacteriaceae described in the present study hybridised with a DNA probe specific for the gene encoding
AAC(3)IV, and that seven of the eight isolates were also resistant to hygromycin $B$.

Resistance to apramycin was transferable in six of the eight clinical isolates. A DNA probe specific for the gene encoding the enzyme AAC(3)IV hybridised with individual plasmids present in four isolates with transferable resistance, and also with plasmids present in their respective transconjugants. In contrast, although the probe reacted with whole-cell DNA of two further isolates with transferable resistance, no hybridisation was observed with extracted plasmid DNA, suggesting a chromosomal location for the gene. The observation that the probe did hybridise with plasmid DNA in transconjugants derived from the latter two isolates suggests transposition of the gene from the chromosome to a plasmid during conjugation. Several workers have reported insertion sequences associated with the genes encoding resistance to apramycin and hygromycin $B,{ }^{10,13}$ which is compatible with these observations.

With the six isolates in which apramycin resistance was found to be transferable, resistant transconjugants always acquired resistance to hygromycin B. In transconjugants produced by three donor isolates, only a single plasmid was transferred suggesting that the genes for resistance to apramycin and hygromycin B were linked on the same plasmid. These observations are in agreement with the previously reported finding that the genes for resistance to apramycin and hygromycin B are in the same operon and would thus be transferred jointly, ${ }^{11}$ but with transconjugants from other donors such linkage could not be inferred as more than one plasmid was transferred. However, one isolate (E550), which transferred more than one plasmid in mating experiments, gave rise to a gentamicin/apramycin-sensitive variant on subculture. This variant, which had lost a single plasmid, also became sensitive to hygromycin $\mathbf{B}$, indicating that both resistance genes were encoded by this plasmid.

As apramycin and hygromycin B have never been used in human medicine, the most likely explanation for the emergence of resistance to gentamicin and apramycin due to production of AAC(3)IV in human isolates of Enterobacteriaceae, and in particular $E$. coli, is that the genetic determinant of resistance has been acquired either directly or indirectly from gentamicin/apramycin-resistant bacteria of veterinary origin. For example, apramycin-resistant $S$. typhimurium phage type $204 \mathrm{c}$ originally isolated from cattle, was also subsequently isolated from man. ${ }^{6}$ Although infection or colonisation of man with such organisms may be transient, the genes encoding apramycin resistance may be transferred by conjugation to other strains of the Enterobacteriaceae found in the normal human intestinal flora. Such inter-generic transfer of a plasmid encoding resistance to apramycin has recently been reported in cattle. ${ }^{7}$ In the present study, restriction enzyme analysis of the plasmids encoding resistance to apramycin and hygromycin $\mathrm{B}$ in the $E$. coli (E179) and K. pneumoniae (K180) isolates from 
the same patient were very similar, suggesting that inter-generic plasmid transfer had occurred in a human host.

An alternative explanation for the emergence of gentamicin/apramycin resistance resulting from the production of AAC(3)IV in bacteria in man, is that the resistance trait evolved independently from that seen in bacteria from animals, under the selection pressure of gentamicin and tobramycin usage in clinical medicine. According to this hypothesis, it is reasonable to expect that other species of Enterobacteriaceae besides $E$. coli and Salmonella spp. would also exhibit resistance to gentamicin and apramycin resulting from the production of AAC(3)IV. However, this does not seem to be the case, as shown by analysis of isolates of Klebsiella and Enterobacter spp. referred to the Laboratory of Hospital Infection from UK hospitals. Between 1987 and 1991, only two $(0 \cdot 6 \%)$ of 306 gentamicin-resistant Klebsiella spp. (not including isolate $\mathrm{K} 180)$ and one $(0.7 \%)$ of 144 gentamicinresistant Enterobacter spp. were also resistant to apramycin (R. C. George, unpublished observations). Similarly, Lovering et al. ${ }^{15}$ reported that while apramycin resistance was detected among two of 18 gentamicin-resistant isolates of $E$. coli, it was not detected among 72 isolates of other genera including Klebsiella, Citrobacter, Enterobacter, Serratia, Proteus and Providencia spp. Thus, apramycin resistance among Enterobacteriaceae isolated from man is found predominantly among $E$. coli $i^{9,11,15}$ and Salmonella spp. ${ }^{6}$ which are species known to spread from animals to man. We have insufficient clinical and epidemiological data to determine whether the patients infected with the gentamicin/apramycin-resistant $E$. coli reported here acquired the infecting organisms either directly or indirectly from veterinary sources or whether the isolates were components of the patients'

\section{References}

1. Wray C, Hedges RW, Shannon KP, Bradley DE. Apramycin and gentamicin resistance in Escherichia coli and salmonellas isolated from farm animals. $J$ Hyg 1986; 97 : 445-456.

2. Wick WE, Welles JS. Nebramycin, a new broad-spectrum antibiotic complex. In: Hobby GL (ed) Antimicrobial agents and chemotherapy-1967. Ann Arbor Michigan, American Society for Microbiology. 1968: 341-348.

3. Ryden R, Moore BJ. The in vitro of apramycin, a new aminocyclitol antibiotic. J Antimicrob Chemother 1977; 3: 609-613.

4. Chaslus-Dancla E, Lafont JP. Resistance to gentamicin and apramycin in Escherichia coli from calves in France. Vet Rec 1985; 117: 90-91.

5. Davies J, O'Connor S. Enzymatic modification of aminoglycoside antibiotics: 3-N-aminoacetyltransferase with broad specificity that determines resistance to the novel aminoglycoside apramycin. Antimicrob Agents Chemother 1978; 14: 69-72.

6. Threlfall EJ, Rowe B, Ferguson JL, Ward LR. Characterization of plasmids conferring resistance to gentamicin and apramycin in strains of Salmonella typhimurium phage type $204 \mathrm{c}$ isolated in Britain. $J$ Hyg 1986; 97: 419-26.

7. Hunter JEB, Shelley JC, Walton JR, Hart CA, Bennett M. Apramycin resistance plasmids in Escherichia coli: possible own bacterial flora that had acquired resistance genes from other organisms (e.g., Salmonella spp.) of veterinary origin. Although some of the isolates belonged to serogroups $\mathrm{O} 8, \mathrm{O} 75$ and $\mathrm{O} 117$, which occur commonly in animals (Dr C. Wray, personal communication), these serogroups are also common among human clinical isolates (Dr T. Cheasty, personal communication).

The seven clinical isolates of gentamicin/ apramycin-resistant $E$. coli reported here belonged to various serogroups, showed distinct plasmid and antibiotic-resistance profiles and were from various geographical locations, suggesting that they were not related epidemiologically. Although the number of isolates described here is small, resistance to apramycin is not routinely investigated in clinical laboratories, and therefore, the extent of the problem is unknown. However, it should be noted that in a recent study of gentamicin-resistant $E$. coli isolated in a hospital in Liverpool, $26 \%$ of the isolates (a figure similar to that noted in the present study) were resistant to apramycin. ${ }^{11}$ The incidence of resistance to gentamicin remains relatively low in bacteraemia isolates of $E$. coli in the UK $(1-2 \%),{ }^{15,16}$ but the fact that clinical isolates of bacteria resistant to gentamicin and apramycin resulting from the production of AAC(3)IV have also been detected in Belgium ${ }^{9}$ and Spain $^{10}$ suggests that the problem may be widespread. Clearly, further work is needed to study the epidemiology of the problem, both in human clinical and veterinary settings.

We thank Dr W. Piepersberg, University of Munich, for providing plasmid pWP701 and Dr T. Cheasty, Laboratory of Enteric Pathogens, Central Public Health Laboratory, for typing the $E$. coli isolates. We also thank Dr C. Wray, Central Veterinary Laboratory, Weybridge for helpful discussions. An abstract describing part of this work has been published in the Proceedings of the 5th European Congress of Clinical Microbiology and Infectious Diseases (Oslo, September 1991).

transfer to Salmonella typhimurium in calves. Epidemiol Infect 1992; 108: 271-278.

8. Chaslus-Dancla E, Martel J-L, Carlier C, Lafont J-P, Courvalin P. Emergence of aminoglycoside 3-N-acetyltransferase IV in Escherichia coli and Salmonella typhimurium isolated from animals in France. Antimicrob Agents Chemother 1986; 29 : $239-43$.

9. Chaslus-Dancla E, Glupczynski Y, Gerbaud G, Lagorce M, Lafont JP, Courvalin P. Detection of apramycin resistant Enterobacteriaceae in hospital isolates. FEMS Microbiol Lett 1989; 61: 261-266.

10. Salauze D, Otal I, Gomez-Lus R, Davies J. Aminoglycoside acetyltransferase 3-IV (aacC4) and hygromycin B 4-1 phosphotransferase $(h p h B)$ in bacteria isolated from human and animal sources. Antimicrob Agents Chemother $1990 ; 34: 1915-1920$.

11. Hunter JEB, Hart CA, Shelley JC, Walton JR, Bennett M. Human isolates of apramycin-resistant Escherichia coli which contain the genes for the AAC(3)IV enzyme. Epidemiol Infect 1993; 110 : 253-259.

12. Kado CI, Liu S-T. Rapid procedure for detection and isolation of large and small plasmids. $J$ Bacteriol 1981; 145: 1365-1373.

13. Brau B, Pilz U, Piepersberg W. Genes for gentamicin-(3)-Nacetyltransferases III and IV: Nucleotide sequence of the AAC(3)-IV gene and possible involvement of an IS 140 element in its expression. Mol Gen Genet 1984; 193: 179-187. 
14. Moxon ER, Deich RA, Connelly C. Cloning of chromosomal DNA from Haemophilus influenzae. Its use for studying the expression of type 6 capsule and virulence. $J$ Clin Invest 1984; 73: 298-306.

15. Lovering AM, Bywater MJ, Holt HA, Champion HM, Reeves DS. Resistance of bacterial pathogens to four amino- glycosides and six other antibacterial and prevalence of aminoglycoside modifying enzymes, in $20 \mathrm{UK}$ centres. $J$ Antimicrob Chemother 1988; 22 : 823-839.

16. George RC, Norbury PB, James D. Surveillance of antibiotic resistance in England and Wales. J Med Microbiol 1992; 36: $17-20$. 